\title{
ВОЗВРАЩЕНИЕ КИТАЯ НА НАЦИОНАЛЬНЫЙ ПУТЬ РАЗВИТИЯ В ЭПОХУ ГЛОБАЛИЗАЦИИ: ЗНАЧИМОСТЬ И ВЫВОДЫ ДЛЯ РОССИИ
}

\author{
Шевченко В. Н. *
}

В статье с позиций мир-системного анализа показаны причины больших успехов, которые достигнуть китайским государством-цивилизацией в последние десятилетия. Эти успехи связаны с тем, что Китай вернулся на свой национальный (цивилизационный) путь развития, с которого его заставили сойти внешние условия - экспансия колониальных держав в XIX-XX вв. Модернизационный рывок основывается на широком использовании традициионных институтов китайской цивилизации, которые складывались на протяжении тысячелетий и которые в сегодняшних условиях оказались способными к развитию, соединению с социалистической идеологией и достижениями общества модерна. В статье показана огромная значимость для России китайского опьта использования исторической традиции и в связи с этим сделан ряд выводов.

Ключевые слова: глобализация, однополярный мир, полицентризм, китайская цивилизация, российская (русская) цивилизация, мир-системный анализ, традиция, институциональная матрица цчивилизаџии, нацииональный путь развития.

From the position of the world-system analysis the article shows the reasons for the great successes achieved by the Chinese 'state-civilization' in the last decades. These successes have been achieved due to the fact that China has returned to its national (civilizational) development path, which it had to leave under pressure of the external conditions, $i$. e. the expansion of the colonial powers in the $19^{\text {th }}-20^{\text {th }}$ centuries. Modernization breakthrough is based on the widespread use of traditional institutions of Chinese civilization, which have been formed over thousands of years and which currently have been able to develop and to connect with the socialist ideology and the achievements of the modern society. The article shows the tremendous importance of the Chinese experience in the use of the historical tradition for Russia, and a number of conclusions are drawn in this connection.

Keywords: globalization, unipolar world, polycentrism, Chinese civilization, Russian civilization, world-system analysis, tradition, institutional matrix of civilization, national development path.

Старт политике реформ и открытости, которую проводит современный Китай, был дан 40 лет назад - в декабре 1978 г., и на последнем ХІХ съезде КПК были

* Шевченко Владимир Николаевич - д. ф. н., профессор, главный научный сотрудник сектора философских проблем политики Института философии РАН. E-mail: vladshevchenko@mail.ru.

Век глобализации 3/2018 106-119

DOI: $10.30884 / v g l o b / 2018.03 .10$ 
подведены ее итоги. Они оказались настолько впечатляющими, что китайский лидер Си Цзиньпин в октябре 2017 г. объявил, что Китай вступает в новую эпоху. Предстоящие реформы будут приобретать все более масштабный характер, с тем чтобы к 2021 г. построить в Китае среднезажиточное общество, а к 100-летнему юбилею КНР в 2049 г. осуществить всестороннее построение модернизированного социалистического государства.

Теоретическое, философское осмысление огромного китайского опыта последних десятилетий, выводов и уроков для российского общества, которые ему еще предстоит усвоить и использовать, - весьма сложная задача. Успешное решение поставленной задачи требует прежде всего особого внимания к вопросам методологического характера.

Обращаться к изучению опыта Китая можно по-разному. Весьма перспективным выступает изучение сходства исторических судеб России и Китая, тех путей, по которым они шли на протяжении последних столетий. А наступление нового этапа глобализации помогает глубже понять объективные причины сближения Китая и России в XXI в.

Первый этап глобализации, как известно, был связан с попыткой интенсивной реализации ее неолиберальной модели в условиях сложившегося в начале 90-х гг. $\mathrm{XX}$ в. однополярного мира. В эти годы приобретает огромную популярность ее истолкование как универсализации, становления единых для всех государств структур, связей и отношений в различных сферах общественной жизни. И в западной, и в отечественной литературе энергично обсуждается идея устарелости национальных государств, границ между их территориями, появления «нового» человека, индивидуалиста-кочевника. Немалое количество материалов с обоснованием такой позиции - Родина там, где мне хорошо, - было опубликовано и в российской печати в 90 -е гг.

Однако вопреки всем прогнозам глобализация неожиданно столкнулась с одним невидимым препятствием. Вместо постоянного развития, которое прочили процессам универсализации, становятся реальностью не только финансовые и экономические кризисы, но и растущее противодействие ей со стороны национальных культур народов мира. В этой ситуации национальному государству независимо от его политической формы самой жизнью «возвращается» главная функция - быть важнейшим инструментом установления оптимального баланса между внутренними и внешними факторами развития, между включенностью страны в мировые глобальные торгово-экономические, промышленно-технологические, научно-информационные, интернет-связи и стремлением ее народа к сохранению своего суверенитета, идентичности, к реализации целей национального развития, к созданию максимально благоприятных для этого внешних и внутренних условий.

Данное обстоятельство в сочетании с другими столь же важными факторами обозначило в первые десятилетия нынешнего столетия начало практического перехода глобализации к новому этапу - от однополярного мира к полицентричной модели мирового развития. Мировой порядок меняется в связи с изменением баланса сил. Здесь важно различать два аспекта проблемы, на что справедливо обращается внимание в работе Л. Е. Гринина [2016: 4]. Есть конкретный ход со- 
бытий и борьбы стран, предугадать который очень сложно. А есть объективные тенденции и причины, которые делают этот процесс неизбежным (гегелевскомарксов «старый крот» истории, который роет медленно, но хорошо). Об этой стороне вопроса и пойдет речь в настоящей статье. Движение мира по пути глобализации продолжается, это объективный процесс, но в последнее время жизнь расставляет другие приоритеты.

Сегодня на всех уровнях говорят о наступлении новой исторической эпохи. Девиз новой современности - двигаться вперед всем вместе, но каждый идет своей дорогой, своим путем. Большие государства цивилизационного типа, или государства-цивилизации (Китай, Иран, Россия, Турция, Индия, Бразилия), становятся или уже стали отдельными центрами силы полицентричного мира, впрочем, как и некоторые межгосударственные образования, например Евросоюз. Но особенности указанных государств-цивилизаций состоят в том, что они возвращаются, каждое по-своему, на утраченный ранее национальный путь развития. В полной мере это относится и к Китаю. Американский политический деятель Г. Киссинджер в своей книге особо отмечает это очень важное обстоятельство: «Китай видит себя не поднимающейся, а возвращающейся на свое законное место державой, доминировавшей в своем регионе в течение двух тысячелетий и, по мнению китайцев, временно смещенной со своего места колониальными эксплуататорами. Китай не рассматривает перспективу сильного Китая как неестественный вызов мировому порядку» [Киссинджер 2014: 584].

Начинается новый, более масштабный этап глобализации, а Россия все еще стоит перед выбором, в каком направлении ей двигаться, и, кажется, никакие доводы пока не смогли примирить две главные противоположные точки зрения. Сторонники одной из них утверждают, что российская цивилизация есть неотъемлемая, хотя и отставшая в своем развитии, часть европейской цивилизации. Согласно второй точке зрения, она есть особая, «неподражательная» цивилизация, впрочем, такими являются и другие названные государства-цивилизации.

Изучение масштабов схожести исторических путей России и Китая в последние столетия позволяет выдвинуть дополнительные доводы в пользу второй из указанных точек зрения. Это сходство носит не только эмпирически наглядный характер, но и глубоко сущностный. Многое в этом отношении может подтвердить обращение к мир-системному анализу, которому не уделяется того внимания, которого он заслуживает как современная методология анализа исторического процесса.

Г. Дерлугьян, один из учеников И. Валлерстайна, общепризнанного лидера школы мир-системного анализа, отметил, что его учитель подверг сомнению результаты исследований всемирной истории, полученные при использовании целого ряда односторонних методологических установок. Главный труд И. Валлерстайна «Мир-система Модерна. I-IV» (The Modern World-System) хотя и носит в основном политэкономический характер, но имеет большое теоретико-методологическое значение. Его «мир-система - это не модернизация, не формация и не цивилизация» [Дерлугьян 2015]. Он синтезирует эти подходы на основе введенного им понимания капитализма как единой экономической мир-системы, как исторического капитализма. Новый взгляд на историю помог на основе огромно- 
го эмпирического материала показать реальное воздействие внешних факторов, прежде всего экономических связей и отношений, на общий ход исторического развития отдельного региона или страны в целом. Именно внешний, западный фактор становится тем фактором, который препятствует превращению незападных стран из традиционных обществ в общества современные, формированию в них общества модерна, несмотря на все усилия того же Запада. По мнению И. Валлерстайна, великая иллюзия теории модернизации состояла в обещании сделать всю систему ядром без периферии. Сегодня стало очевидным фактом, что эта цель недостижима.

Отечественный автор Б. Ю. Кагарлицкий в этой связи особо подчеркнул, «что для русской исторической традиции оказалось характерно преувеличение роли внешнеполитических факторов, недооценка внешнеэкономических и крайне слабое понимание связи между первыми и вторыми» [Кагарлицкий 2004: 12]. Он дал собственную интерпретацию мир-системного анализа И. Валлерстайна для изучения истории российского общества. Этот анализ оказался весьма продуктивным, на богатом фактическом материале было показано, как более развитая экономика Запада конкретно воздействует на торможение и отставание российской экономики, как осознание этого обстоятельства влияло на характер политических решений, принимаемых российской верховной властью, и к каким результатам они приводили.

Единая экономика западноевропейских стран (западноцентричная мир-экономика) начинает постепенно расширяться с наступлением эпохи Великих географических открытий до размеров глобальной единой исторической мир-системы, что привело к возникновению в последнем центра (ядра) и периферии ${ }^{* *}$, которые оказываются связанными неравноправными, но все более тесными торгово-финансовыми узами.

Главная особенность возникающего капитализма как мир-системы заключается в том, что внутри него складывается устойчивое, международное (межгосударственное) разделение общественного труда, которое имеет решающее значение для понимания коренных различий в развитии капиталистической Европы и остального мира, в том числе Китая и Российского государства. В хозяйстве стран этих регионов все большее место занимает экспорт сырья и импорт готовых товаров из метрополий. При таком характере экономических отношений центра и периферии они не укладываются в линейную шкалу временных координат «опережение - отставание».

Конечно, в этих периферийных империях, в других обширных регионах незападного мира под воздействием экономического давления со стороны западных колониальных империй начинают протекать процессы модернизации. Но это были не догоняющие модернизации (по крайней мере, до середины XIX в.), а точечные модернизации некоторых отраслей хозяйства, имевшие целью удовлетворение потребностей стран Запада в необходимых товарах, то есть вызванные по

** И. Валлерстайн вводит различение между полупериферией и периферией, между теми, кто уже включен в западноцентричную мир-экономику, и кто еще дожидается своего включения (incorporation) в нее. Грань между ними исторически быстро изменялась, некоторые исследователи, в том числе Б. Ю. Кагарлицкий, пользуются одним понятием «периферия» при обобщенном взгляде на процессы становления капитализма как единой мир-системы. 
большей части внешними причинами. Более того, отдельные факты такой модернизации не могут изменить общей оценки той устойчивой тенденции развития хозяйства в этих странах, которую И. Валлерстайн называет общим словом «деиндустриализация». Иными словами, происходит упадок и разрушение традиционного аграрного хозяйства, прежде всего мануфактурного производства, которые складывались веками, соответственно, всего жизненного уклада страны. Из четырех регионов, бывших предметом его тщательного изучения (Российская империя, Индийский субконтинент, Османская империя, Западная Африка), только Россия имела «ограниченные способности противостоять деиндустриализации» [Валлерстайн 2016: 188].

Китай не выбивается из этого общего ряда, хотя его история имела некоторые существенные особенности, связанные с его стремлением к закрытости на протяжении многих столетий. Средневековый Китай, как отмечал классик английской политической экономии Адам Смит в своем труде «Исследование о природе и причинах богатства народов» (1776), являлся образцом страны, шедшей тем путем развития в направлении экономической зрелости, который он называет «естественным путем к изобилию». Напротив, Голландия рассматривалась им как совершенно противоположный образец страны, шедшей к экономической зрелости европейским путем, который А. Смит называет противоестественным и ложным. «При естественном ходе вещей большая часть капитала направляется, прежде всего, в земледелие, затем в мануфактуру и в последнюю очередь во внешнюю торговлю... Но хотя такой естественный порядок вещей должен был в известной степени иметь место в любом обществе, во всех современных европейских государствах он во многих отношениях оказался перевернутым на голову» [Смит 1962: 384]. После поражения Китая в Первой опиумной войне все хозяйство страны приходит в упадок. Блестящая цивилизация Востока постепенно опустилась до уровня полуколониального, полуфеодального общества. Страна пережила в первой половине XX в. целую эпоху национально-освободительных революций, гражданских войн и первых попыток индустриализации.

Периферийный тип развития есть прежде всего зависимое (а отсюда и отсталое) развитие, не имеющее устойчивых самостоятельных импульсов к постоянному и целостному развитию всего социального организма. Преодоление одного вида отсталости в результате назревших реформ приводит в скором времени к появлению другого ее вида при сохранении, что важно отметить, зависимого типа развития. Отсюда постоянная череда реформ и контрреформ, не приводящая к преодолению ни отсталости, ни зависимости. Но до определенного времени такое состояние народного хозяйства в некоторых больших государствах-цивилизациях уравновешивается военно-политической мощью, укреплением имперской вертикали власти.

Для периферийных стран путь развития оказывается принципиально иным, чем для стран, входящих в центр глобальной капиталистической мир-системы. Неизбежный распад незападных государств-цивилизаций предопределен переходом центра к империалистической стадии развития. Вывоз товаров сменяется вывозом капитала, что быстро создает как экономические, так и политические условия для неизбежных национально-освободительных революций в этих странах. 
Общее в их судьбах состояло в том, что насаждаемый сверху капиталистический уклад, рост национальной буржуазии, сохранение традиционного аграрного и ремесленного производства приводили к резкому обострению всех противоречий в обществе. Государства-цивилизации, как и другие большие и малые государства, продолжали оставаться по типу культурной матрицы традиционными обществами. Их распад был предопределен последовавшими на этой стадии экономическими и политическими реформами, ставившими целью разрушение и замену базовых структур традиционного общества. Каждому из этих государств цивилизационного типа была уготована в XX в. своя судьба.

Со второй половины XX в. начинается настоящее возрождение Индии, Ирана, Китая, Турции, других больших стран. Но и тогда они остаются в своей основе традиционными обществами, хотя и испытавшими самые разнообразные воздействия - экономические, политические, идеологические - со стороны развитых государств и разных идеологий.

К концу XX в. становится очевидным, что незападные государства-цивилизации не только не смогли стать капиталистическими государствами по западному образцу, несмотря на все усилия сторонников теории модернизации, но теперь они уже и не смогут стать таковыми. И потому ядро их культурной матрицы остается прежним, хотя в каких-то местах матрица оказалась поврежденной и измененной. Это главный вывод из обращения к мир-системному анализу.

С начала нового периода истории - перехода к полицентричности, многовариантности в мировом развитии - в продвижении больших государств-цивилизаций по национальному пути развития на первый план все больше выходит сознательное стремление к ускорению, к форсированному развитию с целью преодоления отсталости и зависимости. Приобретает ли мобилизационная модель развития черты обгоняющей модернизации - это большой вопрос. Но дело здесь в другом.

Понятию модернизации постепенно возвращается прежний смысл, которым оно обладало до начала - середины 50-х гг., когда появляется созданная прежде всего в Америке теория модернизации для развивающихся стран. Она теперь, как и раньше, все больше означает модернизацию промышленности, создание современного индустриального производства, современной инфраструктуры, достижение высокого научно-технологического уровня развития, под которым нередко подразумевается вступление в пятый и шестой технологические уклады. Китай говорит о социалистической модернизации, то есть модернизации, направленной на реализацию целей социализма с китайской спецификой. С современной Россией дело обстоит сложнее. Преобразование российского общества в современное общество, в общество модерна, как того потребовала тридцать лет назад навязанная стране теория модернизации, потерпело стратегическую неудачу [Шевченко 2011]. Но вот куда и как двигаться дальше, остается во многом неясным. Опыт Китая помогает здесь многое понять.

Императивом дальнейшего развития по национальному пути становится возвращение к исторической традиции. В последнее время ее все больше начинают трактовать как культурную матрицу (или культурный код) особой локальной цивилизации, которая складывалась на протяжении многих столетий, а нередко, как 
в Китае, и тысячелетий. Институциональная теория матриц, развивавшаяся сначала в теории эволюционной экономики, теперь активно вторгается в социальную философию. Применительно к этой сфере речь идет в первую очередь о социальных институтах, выступающих системной основой культурно-исторической матрицы общества. Институциональная теория матриц утверждает, что существует два типа институциональных матриц (незападная и западная) [Кирдина 2014; Кондрашова 2014]. В ходе исторического развития, как показали исследования, они взаимно обогащают друг друга, но тип матрицы, сложившийся в ходе многовекового развития отдельной локальной цивилизации и ставший ее прочной исторической основой, не меняется.

В незападной матрице выделяется по крайней мере три главнейших института - тип государственности как жестко централизованная вертикаль власти, коммунитарная идеология, редистрибутивный тип экономики как прямое распределение накопленного общественного богатства. Все три компонента взаимно связаны и взаимно влияют друг на друга.

В связи с этим обсуждается вопрос о том, что при определении понятия «незападная цивилизация» в его содержание должен включаться также и тот природный ареал, в котором она формируется и развивается и который определяет направленность, канал исторической эволюции цивилизации, а следовательно, ее место и особый путь во всемирно-историческом процессе. Западная цивилизация представляет собой иной, «социологический» культурно-исторический тип общества, который тоже в эпоху Средневековья представлял традиционный тип общества, но затем пережил радикальные перемены. В основе цивилизации традиционного типа лежат аграрный тип производства, естественные производительные силы и природные запасы сырья разного рода, имеет место сращенность непосредственного производителя-крестьянина с землей. Западное общество в ходе индустриальной революции уничтожает аграрный способ производства именно как свою естественную основу и все, что с ней связано в обществе. Это означает не просто смену общественного способа производства, главное, что связь общества, социума с естественной средой обитания носит теперь все менее производственный характер, поскольку сырье ввозится во все больших количествах из колониальных и зависимых стран, а взамен им продают готовые товары.

Западное общество модерна, возникнув на определенной территории, навязывает модель своего устройства другим незападным странам, в которых так и не произошло радикального переворота в способе производства, прежде всего благодаря тем неравноправным экономическим связям, которые складывались между ними в течение последних столетий. Превращение сущности западной цивилизации в характеристику универсальной цивилизации, что имеет большое распространение в литературе, затрудняет понимание перспектив развития отдельного незападного государства-цивилизации и постоянно ставит под сомнение признание своего особого, национального пути у каждого из них.

Государство есть главный, системообразующий элемент организации общественной жизни во всех незападных странах. В области государственного строительства можно увидеть сходство в том, что все такого рода страны воспроизводят согласно своей культурной матрице институт высокоцентрализованного госу- 
дарства. В России на протяжении столетий каждый конкретно-исторический тип государства (Русское централизованное государство, Российская империя, Советский Союз, Российская Федерация) воспроизводит в главном одну и ту же матрицу государственности. В истории Китая протекали аналогичные процессы. Сменялись правящие династии, но сохранялась имперская форма правления. Л. И. Кондрашова, описывая институциональную матрицу китайской цивилизации, подчеркивает, «что главный итог долгой китайской истории - само государство» [Кондрашова 2014: 48].

В литературе существует устойчивое мнение, что сторонники этой точки зрения являются «имперцами», стоят на позициях возвращения Китая или России к империи. Не так давно дискуссии в отечественной литературе были весьма жаркими [см., например: Ясин 2007; Паин 2003]. Но суть дела здесь в следующем. Если государство-цивилизация не смогло раньше построить общество модерна, которому присуща другая культурная матрица, то сегодня тем более вопрос о радикальной смене матрицы снимается с актуальной повестки дня. Вертикаль власти остается условием существования, воспроизводства и, более того, условием форсированного рывка вперед. Без ее наличия, без мягкой или жесткой авторитарности, в зависимости от обстоятельств, невозможно создание благоприятных внешних условий, тем более мобилизация общества для достижения больших целей стратегического характера. Многие черты империи ушли в прошлое, многое сделано с точки зрения формирования правовых основ отношений между государственной властью и народом, здесь нужен конкретный анализ. Но, пожалуй, остается главное в отношениях между людьми в российском, как, впрочем, и в китайском обществе. Речь идет о принципиально ином типе социальности.

Здесь уместно вспомнить К. Маркса. Известно противопоставление К. Марксом личных отношений непосредственного господства и подчинения между людьми и вещного характера отношений между ними, оно указывает на важность исторического подхода для правильного понимания субординации цивилизаций добуржуазной (аграрной) и западной (индустриальной, техногенной). Индивиды не могут подчинить себе собственные общественные связи и отношения, пока они их не создали [Маркс, Энгельс 1968]. Личные связи и отношения непосредственного господства и подчинения определяют не только властно-управленческую структуру общества сверху донизу, отношения собственности, но и сам тип довещной, то есть личной формы социальности как таковой. Более высокий исторический тип - это вещные отношения между людьми, возникающие только в таком обществе, в котором происходит индустриальная революция и появляется иной тип социально-классовой структуры и в котором в определяющей степени начинают господствовать рыночные отношения между трудом и капиталом. В том случае, когда незападным странам навязывается либеральная модель государства как якобы оптимальная для них модель политического и экономического устройства, принципиальное отличие личных и вещных, опосредствованных вещным миром отношений между людьми нередко преднамеренно игнорируется с весьма негативными для этих стран практическими последствиями. Волевым усилием нельзя преодолеть неразвитость и особость и никаким декретом или указом нельзя преодолеть доминирующие в обществе сверху донизу отношения непосред- 
ственного, личного господства-подчинения между людьми и в структуре политической власти, и в сфере социально-экономических отношений, в том числе и в отношениях между властью и общинным (артельным) типом разных производственных объединений.

Институциональная матрица государственности, конечно, не остается неизменной. Она изменяется, и в логике истории это должно происходить по законам собственной эволюции, а не путем насильственного слома. Этому учит современный отечественный и китайский опыт. Государство в современном Китае квалифицируется многими политологами как авторитарное. Поэтому когда говорят, что сохранение авторитаризма является следствием низкой политической культуры в стране, то здесь дело, скорее всего, не в политической культуре людей в смысле их отсталости или приверженности архаике. В обществах незападного типа на современном этапе складывается и развивается уже своя политическая культура, свое понимание демократии, которые напрямую нельзя сравнивать с политическими культурами других цивилизаций, а тем более западной цивилизации. Когда централизованная вертикаль власти считается архаикой, от которой необходимо отказаться, которую нужно радикально сломать, то всякие попытки ее революционного слома ведут к ожесточенным социальным столкновениям (примеры: Тяньаньмэнь, май 1989 г.; Москва, Белый дом, август 1991 г.). За ними вполне возможен и вероятен распад государства и единого природного ареала цивилизации.

Это обстоятельство помогает понять, почему авторитарная власть объективно, с точки зрения логики истории страны, продолжает оставаться стержневой основой организации общественной жизни, тем более в условиях возрастания роли национального государства на новом этапе глобализации. Как отмечает В. Г. Буров, «авторитарный политический строй адекватен нынешним социокультурным условиям Китая. < ..> Опыт такой страны, как Китай, убедительно свидетельствует о том, что только сильная власть, если хотите, авторитарная власть может ставить долгосрочные цели, в частности такую, как модернизация» [Буров 2013: 169, 171]. Другими словами, если страна выбрала национальную цель развития на долгие десятилетия, то какую альтернативу может предложить любая другая партия, например, идее возрождения китайской нации как ее великой мечте? Единственное позитивное поле деятельности для других партий заключается в том, что они опираются на определенные социальные слои, выражают их специфические интересы и действуют по принципу дополнительности в нормативных рамках национального согласия, которые устанавливает государство и которые поддерживает и одобряет господствующая в обществе идеология. Современные малые партии (в Китае их восемь) активно участвуют в общественнополитической жизни и государственном управлении.

Известный общественный деятель В. Т. Третьяков много раз говорил о глубоком кризисе партийного представительства в российском обществе. В нем должна быть по-иному построена многопартийность. Необходима реальная, а не словесная конкуренция политических идей и лидеров, поэтому современному парламентаризму надо опираться на реальные политические интересы основных сил общества. А эти основные силы и есть те самые многочисленные социальные слои, из которых состоит общество, как апельсин из долек. «Прямое социально-профес- 
сиональное представительство станет реальным народным представительством в российском обществе» [Третьяков 2013: 132]. Такой подход к решению проблемы, на наш взгляд, во многом навеян политическим опытом современного Китая.

В институциональной матрице незападной цивилизации редистрибутивная экономика выступает основным регулятором хозяйственной жизни. Государство выполняет важнейшую функцию планирования и перераспределения общественного богатства, при этом рыночные отношения могут играть важную, но подчиненную роль. Опыт Китая, как многовековой, так и современный, подтверждает это положение. Как отмечают китайские авторы, «государство оставляет за собой контроль над ключевыми отраслями, чтобы тем самым сохранить суверенитет и максимизировать пользу для граждан» [Китайская... 2013: 154-155].

Важно отметить, что рынок, банковская система, частная собственность в современном Китае не остались в наследство от капиталистического прошлого: такого наследства у страны практически не было. Они были созданы социалистическим государством, встроены в общество и используются им как важные и эффективные инструменты государственного управления, способствующие экономическому развитию и процветанию государства. Наличие этих инструментов, однако, не дает оснований считать, что Китай идет по капиталистическому пути, хотя и приносит с собой немалое количество сложных проблем и социальных противоречий ввиду явного несовершенства общества на начальной стадии социализма. Капитализм становится общественным строем лишь тогда, когда идентифицирует себя с государством, когда слой или класс богатых, состоятельных людей «прибирает к рукам» важнейшие рычаги государственного управления.

В Китае есть слой богатых людей, сложился регулируемый государственной властью обширный капиталистический уклад в экономике, но нет капитализма как общественного строя. Власть принадлежит народу в лице социалистического государства. Поэтому сомнительным является утверждение о борьбе капитализма и социализма в современном Китае. Экономика Китая - это социалистическая рыночная экономика. Что касается России, то насильственный слом институциональной матрицы экономики привел ее в состояние глубокого упадка. Для соединения социальной справедливости - вековечной мечты русского (российского) народа - и рыночных механизмов экономики российская власть так и не смогла до сих пор найти грамотного решения.

Культурная матрица выступает исторической основой дальнейшего развития страны, но ее не следует понимать упрощенно. Она часто выступает огромным препятствием для модернизации. Отношение к традиции как к консервативной и даже реакционной силе хорошо известно со времен Просвещения. Такое отношение было господствующим в европейской, отечественной и китайской мысли примерно до середины 1950-х гг.

Поворот в развитии человечества от однолинейного развития исторического процесса к многолинейному намечается в 50-60-е гг. XX в. Это были годы выдвижения и апробации теории модернизации для незападных стран в связи с деколонизацией стран Азии, Африки и Латинской Америки. С тех пор вопрос о соединении стремления этих государств к реформам, к модернизации с исторической традицией приобрел огромную практическую актуальность. Как предложить 
обществу такую идею модернизации, чтобы она соединяла прошлое и будущее, а не противопоставляла их? Первоначально такое соединение приводило к неудачам в 50-60-е гг. прошлого века независимо от характера этой большой идеи либеральной, социалистической, национальной (а скорее всего, националистической).

Цивилизационная матрица обладает огромной инерцией. При этом чем более замкнутым и совершенным является средневековое традиционное государство, тем сложнее его направить на путь перемен, особенно радикальных. В этом отношении китайская цивилизация выступает в истории одним из самых характерных примеров. «Всем китайским революциям, - как отмечает известный китаевед А. В. Виноградов, - начиная с Синьхайской и кончая “культурной”, свойственны общие черты. <..> Традиционная культура и социальная организация были неспособны эффективно ответить на вызовы времени и внешние угрозы, но были еще достаточно сильны, чтобы сопротивляться внутренним попыткам реформирования» [Виноградов 2014: 128].

Мао Цзэдун дважды поворачивал влево (большой скачок и культурная революция), чтобы раскачать традицию, сломать ее, пока традиционное массовое сознание общества смогло преодолеть устойчивый комплекс закрытости, отторгающий все новые идеи и смыслы. В 50-60-е гг. Мао Цзэдун говорит об идеях Конфуция как о реакционных. И только с третьего раза, уже после его смерти и начала политики реформ и открытости Дэн Сяопина, соединение прошлого и будущего пошло в правильном направлении. Как отмечается в одной из обзорных работ группы китайских авторов, «частичное унаследование и развитие традиционной культуры образуют саму суть и истинный смысл культурной модернизации» [Обзорный... 2011: 211]. Такое понимание пришло не сразу и стоило больших жертв.

Россия испытывала те же трудности, когда верховная императорская власть начинала очередную реформу, направленную на преодоление отсталости. Реформы сталкивались с неготовностью населения традиционных взглядов к переменам, что приводило к остановке реформ, откату назад и контрреформам. Трагические страницы Русской революции 1917 г., Гражданская война были вызваны столкновением революционного нетерпения народных масс и жесткой позиции политических консерваторов, полным неприятием ими друг друга, что и привело к полномасштабному военно-политическому конфликту. Это пример того, когда «традиционность вырождается в охранительство, а затем в реакцию. Новация... отрываясь от национальных корней, также вырождается - в нигилизм и революционаризм» [Кара-Мурза 2010: 33].

Возвращение к национальному пути дает ясный ответ на вопрос о том, что является основой дальнейшего развития - историческая традиция или большая идея, задающая стратегические цели дальнейшего развития страны. Это одна из самых интересных проблем философии истории: как соотносятся основа и уток (перенесенные в философию из ткацкого производства), объективные обстоятельства и субъект истории. Дэн Сяопин, отец китайских реформ, к примеру, говорил, что сначала он китаец, а уже потом - коммунист. 
Современный Китай представляет собой гетерогенное, неорганически сложившееся общество, в котором процессы синтеза далеки от своего завершения, причем гетерогенность усиливается наличием многих западных идей, в первую очередь связанных с механизмами функционирования капиталистической экономики. Эта особенность китайского общества позволяет помочь осознать причины широкого распространения самых разных интерпретаций того, чем сегодня является Китай. Среди них - страна возвращается в Средневековье, к феодализму, или страна есть диктатура партийных вождей, или страна есть капитализм, прикрытый красными флагами. И рядом с этими интерпретациями современный Китай это конфуцианский социализм, а современное новое конфуцианство есть главная основа новой китайской «духовной цивилизации». За каждой интерпретацией стоит своя реальность, каждая из них лишь частично интегрирована в целостность. Но КНР позиционирует себя как социалистическую страну, это наиболее значимая сторона в жизни общества, его интегральная характеристика. «B XXI веке научный социализм приобрел в Китае могучую жизнеспособность и жизненную энергию, и сейчас над миром высоко реет великое знамя социализма с китайской спецификой» [Си Цзиньпин 2017]. С этим следует считаться.

В значительной мере ситуация, сложившаяся в китайском обществе, относится и к современной России. Российское общество с начала 90-х гг. прошлого века - это новая очень сложная социальная реальность. В современных российских социальных науках не имеется, по мнению целого ряда авторов, адекватного понятийного аппарата для ее описания и объяснения. Наличие большой идеи, стратегической цели, определяющей суть политико-практической деятельности государства, выступает философско-методологической основой, императивом формирования понятийного аппарата отечественных социальных наук, изучающих современный российский социум и тенденции его развития. В пользу этого заключения говорит весь опыт современного Китая.

Если говорить о тех выводах, которые следует принять во внимание при анализе современных проблем России, то можно назвать три, как мне представляется, самых главных:

1. Россия продолжает оставаться по своей исторической основе, по своей культурной матрице традиционным обществом, которое обретает новые конкретные формы существования и новые смыслы в соединении с большой идеей, со стратегическими целями и задачами, сформулированными на много десятилетий вперед. От их конкретного содержания будет зависеть, в каком направлении российское общество, устремленное в будущее, будет трансформировать исторические традиции прошлого.

2. При любом выборе большой идеи российское общество долгое время будет сохранять свою гетерогенность, неорганичность, и в таком обществе идеология играет особо важную роль именно как интегральная идеология, направленная на удержание, сохранение национального согласия и территориальной целостности.

3. Россия, как и Китай, должна видеть себя не поднимающимся, а возвращающимся на свое законное место государством-цивилизацией, которое складывалось и развивалось на огромной евразийской территории, по крайней мере с при- 
нятием христианства. Наступающий новый этап глобализации открывает новую историческую эпоху - эпоху полицентричности, он принесет с собой и новый мировой порядок, в котором Россия, Китай, Индия, Турция, Бразилия, другие большие государства-цивилизации станут сильными, самостоятельными и весьма влиятельными центрами силы. Но то, как будут складываться отношения на мировой арене между этими отдельными центрами силы, требует отдельного разговора.

\section{Лuтература}

Буров В. Г. Стратегия китайского государства в контексте российского опыта // Динамика взаимодействия внутренних и внешних факторов и вектор развития российского общества / под ред. В. Н. Шевченко. М. : ИФ РАН, 2013.

Валлерстайн И. Мир-система Модерна. Т. ІІІ. Вторая эпоха великой экспансии капиталистического мира-экономики. 1730-1840-е годы. М. : Русский фонд содействия образованию и науке, 2016.

Виноградов А. В. Китай и модернизация // Китайская цивилизация в глобализирующемся мире: в 2 т. Т. 1 / под ред. В. Г. Хороса. М. : ИМЭМО РАН, 2014.

Гринин Л. Е. Возможности и перспективы формирования нового мирового порядка. Ст. 2 // Век глобализации. 2016. № 1-2. С. 3-18.

Дерлугьян Г. О труде Иммануила Валлерстайна «Мир-система Модерна» [Электронный ресурc]. URL: https://lenta.ru/articles/2015/11/07/derlugian/ (дата обращения: 20.02.2018).

Кагарлицкий Б. Ю. Периферийная империя: Россия и миросистема. М. : Ультра. Культура, 2004.

Кара-Мурза А. А. Соотношение традиции и новации в русской философии истории // Проблемы российского самосознания: архаическое, традиционное и инновационное начала. Материалы 4-й Всероссийской конференции. Москва - Белгород. 27-29 мая 2009 г. / под ред. С. А. Никольского. М. : ИФ РАН, 2010.

Кирдина С. Г. Институциональные матрицы и развитие России: введение в X-Ү-теорию. СПб. : Нестор-История, 2014.

Китайская мечта и мир / под ред. Хуан Хуагуана, Луань Цзяньчжана. Пекин : Издво лит-ры на иностранных языках, 2013.

Кондрашова Л. И. Институциональная матрица китайской цивилизации // Китайская цивилизация в глобализирующемся мире: в 2 т. Т. 1 / под ред. В. Г. Хороса. М. : ИМЭМО РАН, 2014.

Киссинджер Г. О Китае. М. : АСТ, 2015.

Маркс К., Энгельс Ф. Экономические рукописи 1857-1859 годов / К. Маркс, Ф. Энгельс // Соч. 2-е изд. Т. 46. Ч. 1. М. : Гос. изд-во полит. лит-ры, 1968.

Обзорный доклад о модернизации в мире и Китае (2001-2010) / под общ. ред. Н. И. Лапина. М. : Весь мир, 2011.

Си Цзиньпин. Полный текст доклада на 19-м съезде КПК 2017.11.04 [Электронный ресурc]. URL: http://ru.china-embassy.org/rus/ztbd/19sjd/t1507487.htm (дата обращения: 12.03.2018). 
Паин Э. А. Между империей и нацией: модернистский проект и его традиционалистская альтернатива в национальной политике России. М. : Новое изд-во; Фонд «Либеральная миссия», 2003.

Смит А. Исследование о природе и причинах богатства народов. М. : Соцэкгиз, 1962.

Третьяков В. Т. Конец партийности и сословная демократия // Перелом. Сборник статей о справедливости традиций / сост. А. В. Щипков. М. : Пробел-2000, 2013 [Электронный ресурc]. URL: http://shchipkov.ru/12605 (дата обращения: 10.02.2018).

Шевченко В. Н. Модернизация или национальный путь развития // Философские науки. 2011. № 1. С. 46-59.

Ясин У. Фантомные боли ушедшей империи // После империи / под ред. А. М. Клямкина. М. : Фонд «Либеральная миссия», 2007. 